\title{
Cacophony of Religion and Survival Instinct
}

\author{
Dr. Manjula Uppal \\ Associate Prof. (Zoology), S.L. Bawa D.A.V. College, Batala, Distt. Gurdaspur, Punjab, India
}

\begin{abstract}
Culturally developed human being came to adapt religion as a mark of cohesiveness and strength which proved out to be advantageous for their survival. In nature if any population is on a constant rise, the competition to meet the needs become inevitable and ever increasing population becomes a self destructive force. These intra species interactions in human species which are being expressed in the garb of fanaticism are in fact the competitive instinct for survival to meet basic requirements of food, shelter and space which is getting scarce and limited because of meteoric rise in population.
\end{abstract}

Keywords: Primate behaviour, Intra species interaction in humans, Instinct, Social behaviour of man, Fanaticism

\section{Introduction}

In most of the towns and cities especially in India one gets up in the wee hour of night or early morning to the blaring noise of loudspeakers rehearsing and chanting the pious words of all the prevalent religious practices. This cacophonous recitation although supposed to be spiritual with a soothing effect on mind and body, creates a contrary impact. Are we typed up to be ritualistic just in words and not in spirit? Over the years every religion has acquired properties to grow, and all the religious festivities, be it of any religion, are celebrated in a way so as to make a show of strength of that very particular community. Do we practice the religion for our safety at the social level and feel secure out of this cohesiveness?

Basically human species is a social being with an instinct to live in an organised and collective way for the welfare of its species. Animal species which show social behaviour live together in large groups and interact to perform the tasks of the colony. Life originated in the form of single celled entities, which over a period of time aggregated to give rise to multi-cellular living forms showing division of labour for meeting the basic needs of life and were successful in enhancing their life span. Natural selection prevailed upon and multi-cellularity evolved to give rise to a variety of advanced living forms. These forms could survive as solitary individuals or flocked together in groups and became gregarious in habit. Further the animals of same species started interacting for the benefit of each other and these interactions could prove to be beneficial for the species and led to the appearance of behaviours like parental care. Several species showed adaptive behaviour which could evolve in the form of animal aggregates for survival against predators e.g. fish schools, herd of wild beasts and flock of birds, to increase their chances of survival compared to the solitary creatures. A variety of species showed elaborate interactive behaviour and it could progress in the form of socially organised groups with quite many examples of parallel evolution of societies in various species of Kingdom Animalia, like, ants, termites, bees and wasps etc. in invertebrates and mammals in vertebrates particularly primates i.e. monkeys, orang-utans, chimpanzees and humans. Living in groups involves a balance of conflict and cooperation, which is mediated by the costs and benefits associated with living socially. When the benefits of living socially exceed the costs and risks of social life, scientists predict that social cooperation will be favoured. Most primates, including human beings are reported to spend their lives in large social groups and communities. Most nonhuman primate communities are more or less not in contact with member of other communities and are tied to a particular locale and rarely migrate outside their home range. This aloofness from other troops prevents high concentrations of individuals; otherwise it could result in rapid depletion of local resources. Communities usually avoid each other and are aggressive towards outsiders. As a result, social interactions between members of different troops is very rare especially for females, with a notable exception of chimpanzees which often display exciting friendly encounter lasting several hours when chimpanzees from different troops come together following which some of the adult females switch groups. Apparently they are seeking new mates. Occasionally, however, contact between communities of the comparatively unpredictable chimpanzees will develop into genocidal violence. In some forest-living primates, contact between groups of the same species is in the form of specialized territorial defence behaviour. Instead of avoiding each other, groups actively converge near their common territorial border and make hostile displays. Howler monkeys, Indris, Siamanges, and Gibbons all produce exceptionally loud vocalization for this purpose. This is a ritualized, essentially harmless form of aggression that is intended to intimidate members of neighbouring community [1]. Humans too share their social behaviour with the same evolutionary line and are sure to exhibit this as an innate characteristic derived from their ancestors.

The overgrowing population and a social instinct along with cultural development and geographical distribution associated with a higher cranial capacity helped human species to adapt themselves to their surroundings and develop characters in accordance to their particular requirements and as a result of various epigenetic factors could evolve to develop phenotypic differences in their colour, behaviour, face and body contours. They remained separated for a long time and because of

geographical barriers and lesser communication, could create genetic differences and thereby different races. The growing population led to intra species interactions, and to prove their supremacy individuals congregated in the form of groups. As the cultural and social growth proceeded they 


\section{International Journal of Science and Research (IJSR) \\ ISSN (Online): 2319-7064}

Index Copernicus Value (2013): 6.14 | Impact Factor (2014): 5.611

got demarcated from each other and according to their beliefs created different cults and religions. These groups came to occupy diverse areas and on the basis of religion adapted to create different sects. This grouping (groupism) provided them strength, and further growing believes and rituals pitched them against each other. Human interactions and groups gave rise to countries which fought against each other for their territories. Basically, it is a territorial fight which does act at the microcosmic and macrocosmic level. With further swelling population, a fierce battle has erupted among different religious groups, which is getting more and more uproarious and is being displayed in the form of differences at religious level, a cacophonous attitude towards display of religious rituals, fanaticism and terroristic activities.

All the organisms need food, shelter and space to grow and so do the human species. As population increases there erupts a fight among organisms for their basic needs, and all the organisms including human beings are genetically wired to behave in the same way, to compete for their survival. Although it appears to be a fight for basic rights and material things but the basis of every fight is the need of survival which even intelligent human species, as a part of nature, cannot afford to escape.

\section{Conclusion}

Religion as a mean of cohesiveness in culturally developing society of human species, does project the instinct of security and survival. Over and ever increasing population is creating a competition and breeding a sense of fanaticism, contempt and mutual destruction which might be the pedestal for nature to balance its highly evolved species.

\section{Reference}

[1] Social Structure: anthro.palomar.edu > behavior >bahave_2 visited on 5/12/15. 